\title{
THE ENDS OF INFORMATION SYSTEMS RESEARCH: A PRAGMATIC FRAMEWORK ${ }^{1}$
}

\author{
Panos Constantinides \\ School of Economic Sciences \& Administration, Frederick University, \\ Limassol, CYPRUS \{constantinides.p@frederick.ac.cy\} \\ Mike W. Chiasson \\ Department of Management Science, Lancaster University Management School, \\ Lancaster LA1 4YX UNITED KINGDOM \{m.chiasson@lancaster.ac.uk\} \\ Lucas D. Introna \\ Department of Organization, Work and Technology, Lancaster University Management School, \\ Lancaster LA1 4YX UNITED KINGDOM \{l.introna@lancaster.ac.uk\}
}

\begin{abstract}
In this paper, we argue that any effort to understand the state of the Information Systems field has to view IS research as a series of normative choices and value judgments about the ends of research. To assist a systematic questioning of the various ends of IS research, we propose a pragmatic framework that explores the choices IS researchers make around theories and methodologies, ethical methods of conduct, desirable outcomes, and the long-term impact of the research beyond a single site and topic area. We illustrate our framework by considering and questioning the explicit and implicit choices of topics, design and execution, and the representation of knowledge in experimental research-research often considered to be largely beyond value judgments and power relations. We conclude with the implications of our pragmatic framework by proposing practical questions for all IS researchers to consider in making choices about relevant topics, design and execution, and representation of findings in their research.
\end{abstract}

Keywords: IS research practice, rigor and relevance, pragmatism, ethics

\section{Introduction}

Since the 1999 MIS Quarterly special issue on the rigor and relevance of IS research (Benbasat and Zmud 1999; Davenport and Markus 1999; Lee 1999; Lyytinen 1999), there has been a lot of debate around the state of the IS field (King and Lyytinen 2006). The debate can be summarized into key concerns about the interdisciplinary nature of the IS field, and emerging opportunities for spanning the theory-practice

\footnotetext{
${ }^{1}$ Geoff Walsham was the accepting senior editor for this paper. Ola Henfridsson served as the associate editor.
}

divide. It is this latter theory-practice element of the rigor/ relevance debate - which has weighed down on the discipline, and engaged most of the leading figures in the field, for many years (indeed long before the MIS Quarterly special issue in 1999) - that we will take as a starting point for reflecting on the ends of IS research.

To address the theory-practice problem a variety of solutions have been proposed over the years. Robey and Markus (1998) suggest that research can be rigorous and relevant by being made consumable. Benbasat and Zmud (1999) propose that IS researchers should select topics for research that are 
relevant to practitioners' needs while producing implementable knowledge that is written in an accessible style and tone. Baskerville (1999) proposes action research as a practicebased solution to the dilemma. Finally, and more recently, Rosemann and Vessey (2008) suggest relevance can be achieved by producing research that is important to practice, is accessible by practitioners, and can be assessed for relevance through applicability checks.

The underlying assumption in most of these proposals is that the issue of relevance is implicitly one about the production of knowledge and how to ensure that the work is relevant to the ends of practitioners (e.g., transformation of practice), either directly in the research, or indirectly in the publication of findings. While this assumption may be entirely appropriate in understanding relevance, it should not be taken as a given, uncritically. Clearly this is just one possible determination of the relevant ends of IS research, and how it is to be achieved. However, one could also propose a whole range of entirely different and relevant ends for IS research with different audiences, and processes to achieve those ends. For example, one could argue that relevance is scholarship and scientific rigor that pursues general knowledge and serves the long term interests of society rather than the development of knowledge for practitioners whomever they may be. On the other hand, others may suggest that the ends of IS research are meant to transform a particular group, with implications arising from such transformation for other groups.

Such a critical questioning of the ends of IS research brings into sharper focus the need to consider all possible relevant ends - and with it the greater good that researchers, as producers of knowledge, are striving to serve. By suggesting this, we acknowledge that IS researchers will always find themselves entangled in a landscape of conflicting ends that need to be navigated - and this is exactly what makes the question of ends a serious and urgent one. We are also suggesting that such complex individual and collective problems cannot be solved by uncritically accepting only one interpretation of relevance, at the exclusion and expense of others, which may be equally important and transformative, or by bracketing these questions to be handled later or by someone else. Rather we want to suggest that these questions of conflicting ends are intricately tied to all aspects of our research practice and need to be reflected upon, and explicitly dealt with by every researcher. In other words, we believe there is a need for a framework which might guide IS researchers to consider and address this intricate landscape of conflicting ends in an explicit and justifiable way.

One proposed approach for dealing with this landscape of conflicting ends is to make value judgements more explicit through ethical reasoning (Davison et al. 2006), which focuses on ideal ethical categories such as the social contract, individual rights, and moral justice (Kolhberg 1981). Despite its considerable merits, however, the focus on ideal ethical categories has a tendency to exclude and perhaps obscure the local and situated concerns, values, and dilemmas people may face in different and particular contexts (Snell 1996; also see Habermas 1994, p. 120). It has been argued that, beyond the development and use of abstract moral categories to guide ethical research practices, there is a need to consider the situated and emerging ends of IS research (Hirschheim and Klein 2003).

Habermas' work on communicative action $(1992,1998)$ and discourse ethics (1994) has also been proposed as an alternative approach to dealing with the situated and emerging ends of IS research. Specifically, Habermasian ideas toward ethical research have been extensively applied to ethics and IS - from Enid Mumford's ETHICS framework (e.g., Hirschheim and Klein 1994; Mumford 2006) to discourse ethics (e.g., Mingers and Walsham 2010; Stahl 2008). On the one hand, the ETHICS framework provides explicit ethical principles in order to inform moral practices, including the emancipation of human subjects involved in the research. On the other hand, discourse ethics is grounded in a radical approach to democratic participation through communicative acts among those affected by research practice decisions and proposals.

Such approaches to dealing with the situated and emerging ends of IS research place considerable emphasis on ethical and applicative knowledge (Hirschheim and Klein 2003). Ethical and applicative knowledge is conceptualized through phronesis (Aristostle 2006) as an on-going reflective development of prudent knowledge through ongoing action and reflection that is continuously shaped by and imbued with situated values and interests (Hirschheim and Klein 2003, p. 266). Hirschheim and Klein (2003) argue that, to date, the IS field "has focused almost the entirety of its resources on theoretical and technical knowledge, ignoring ethical and applicative knowledge" (p. 268). Similar arguments have also been made elsewhere acknowledging that "the core IS field... is underrepresentative of ethics and IS" (Mingers and Walsham 2010, p. 834).

This research essay addresses and expands upon these arguments by seeking to illustrate how IS research practice involves choices about conflicting ends-implicit and explicit choices about what we value and what we (intentionally or unintentionally) pass over as relevant knowledge for IS research. Our key argument is that any efforts to understand the state of the IS field - especially as reflected through the lens of the rigor/relevance debate - needs to appreciate IS research as a series of conflicting choices and value judg- 
ments, individually and collectively made. These choices shape the research projects and papers we choose to pursue and write about (and those we pass over) and have significant consequences for those affected or passed over by this work. In other words, it is exactly the way we deal with these conflicting choices in our individual research practice that shapes and determines our identity as IS researchers and, consequently, the collective identity of our field.

To open up this landscape of conflicting ends, we develop a pragmatic framework. We draw initially on the pragmatic philosophy of Charles Sanders Peirce (1931-1958) and his idea of a community of inquirers engaging in a continuous process of examination aimed at the discovery of new ways of accounting for the effects and results we are experiencing. Through this discussion we then develop links to recent conceptualizations of phronesis by Habermas (1994) and Flyvbjerg $(2001,2004,2006)$, including the importance of phronetic (i.e., ethical-applicative, value-informed) research. We will argue that the dominant and primarily technical approach (i.e., theory and methodologically driven) adopted by IS researchers necessarily involves ethical choices and value judgments. By acknowledging this, IS researchers can develop a more reflective consideration of how their technical choices are affected by and affect other ends and for whom. These include the anticipated and desired outcomes of the research, the collective and long-term impact of the research for the communities we serve and inform, and the ways in which our choices are fostered, shaped, and restricted by power relations.

The rest of the paper is structured as follows. In the next section, we discuss our pragmatic framework in more detail. This framework is then used to identify key questions IS researchers should ask in engaging the different ends of research inquiry. Following this discussion, we illustrate the value of our framework by considering and questioning the explicit and implicit ends of experimental research — research often considered beyond deliberate questions about ethics, value judgments, and power relations. We conclude with some implications of our pragmatic framework by proposing some practical recommendations IS researchers could employ in questioning and selecting IS topics, designing and executing their studies, and representing their research in publications.

\section{Understanding the Consequences of Different Choices in IS Research}

Peirce's pragmatism provides a philosophical starting point for exploring the different ends in IS research. The main reason for choosing Peirce's philosophy is that it crosses many epistemological divides, having been associated with interpretivism and semiotics (Eco 1979, 1994), positivism (Gruender 1983), realism (Hausman 1993; Sfendoni-Mentzou 1996), and critical social theories (Apel 1982, 1995; Habermas 1992, 1994, 1998). As a result, Peirce's philosophy is capable of supporting and questioning various approaches to IS research (also see Baskerville and Myers 2004; Goles and Hirschheim 2000).

In the next subsection, we discuss Peirce's conceptualization of ethical inquiry against more recent considerations of phronetic research. This discussion is then linked to IS research practice in order to develop key questions IS researchers can ask in critically engaging the choices they make before, during, and after research inquiry.

\section{The Ends of Research Inquiry}

Pierce, following Aristotle, conceptualized ethics as only one part of three interdependent normative sciences, with logic and aesthetics comprising the other two. These three normative sciences are interdependent in that answers to logic (i.e., approaches to reasoning) presuppose conclusions about ethics (i.e., methods of conduct), and answers to ethics presuppose conclusions about aesthetics (i.e., the anticipated and desirable outcomes) (Stuhr 1994). In Peirce's own words (CP $5.611):^{2}$

What does right reasoning consist in? It consists in such reasoning as shall be conducive to our ultimate aim. What, then, is our ultimate aim?...It would seem to be the business of the moralist to find this out, and that the logician has to accept the teaching of ethics in this regard. But the moralist, as far as I can make it out, merely tells us that we have a power of self-control, that no narrow or selfish aim can ever prove satisfactory, that the only satisfactory aim is the broadest, highest, and most general possible aim; and for any more definite information, as I conceive the matter, he [sic] has to refer us to the aesthetician, whose business it is to say what is the state of things which is most admirable in itself.

In terms of IS research, this quote stresses the point that beyond the question of whether practitioners will read and use our rigorous research results arising from certain theoretical assumptions and methodologies, the entire effort rests on

\footnotetext{
${ }^{2} \mathrm{CP}$ refers to Collected Papers of Charles Sanders Peirce (1931-1958). The first number indicates the volume and the second number following the period indicates the paragraph.
} 
choices about the ethical conduct of researchers, and a deliberation about the anticipated and desirable outcomes worth pursuing in IS research. In other words, our choice of logic presupposes questions and answers about ethics and aesthetics.

Our interdependent choices across these ends emerge in a continuous inquiry within a community of inquirers (CP 1.574), which comes to realize the summum bonum or highest good of their collective efforts (CP 1.191; also see Krois 1994). This highest good refers to how people within the community come to collectively think, act, and feel (CP 8.315). The highest good, thus, directly relates to the generation of relevant knowledge by directing and shaping attention toward those collections of thoughts (logic), actions (ethical conduct), and feelings (aesthetics) worth pursuing by the majority within a community of inquirers (Apel 1995). Peirce writes (CP 5.311)

The real is, then, that which, sooner or later, information and reasoning would finally result in, and which is therefore independent of the vagaries of you and me. Thus, the very origin of the conception of reality shows that the conception essentially involves the notion of COMMUNITY, without definite limits, and capable of a definite increase in knowledge.

"The real" is thus the highest good that a community of inquiry comes to experience and realize, within and through its diverse and collective practices over time, as worth pursuing (CP 5.433). This is why the highest good is thought to derive from but also transcend the diverse knowledge and practices in the community (Apel 1995; Habermas 1998). The development and expansion of this transcendental highest good also prompts an expansion of the community of inquiry to include others who see value in the ends, but also debate and participate in the communal assumptions. Thus, the community is not static, but is transformed through a continuous process of inquiry that grows and diversifies in addressing and producing the highest good (Eco 1994).

The process of realizing the highest good and transforming communal practices and values was referred to by Peirce as "critical common-sensism," a productive reflective-learning process whereby ideas and practices are understood in terms of their anticipated and actual consequences (Liszka 1978).

"That is, meaning is not ascribed in a priori terms; rather, it is identified by anticipating 'what if' consequences to potential actions and conduct" (Elkjær and Simpson 2006, p. 3) toward an evaluation of possible solutions "which would hold in the long run" (CP 5.209-211).
Critical common-sensism has strong affiliations to the notion of phronesis $^{3}$ as both are concerned with deliberation about the values and interests of a broader community of inquiry (Flyvbjerg 2001, 2004, 2006; Habermas 1994). Recent commentaries have argued that research needs to move toward phronesis by taking into account situational and value-rational questions in specific organizational and practical settings, such as "where are we going? Is this development desirable? What, if anything, should we do about it?" (Flyvbjerg 2006, p. 375). These questions seek to balance instrumental (i.e., efficiency, getting things done) with value rationality (i.e., which of our local and situated values become affected and how), consistent with Peirce's three normative sciences and their interdependencies. In a striking similarity to Peirce, Flyvbjerg (2006, p. 375) argues that "the key point is the establishment of a better option, where 'better' is defined according to sets of validity claims." The process of inquiry is thus, for both Peirce and Flyvbjerg, ongoing and grounded within a community of inquirers. "Phronetic organization researchers realize that our sociality and history is the only foundation we have, the only solid ground under our feet" (Flyvbjerg 2006, p. 375).

However, Peirce is largely silent about power and its influence on the determination of the ends of research inquiry. Flyvbjerg (2006) offers a way forward by arguing for a broader, more inclusive community of stakeholders currently excluded from research inquiry, but who are affected by it. ${ }^{4}$ Beyond an effort toward more plurality in research inquiry, Flyvbjerg raises the critical question of "Who gains and who loses, and by which mechanisms of power?" (2006, p. 374). Power here is understood to be exercised through various "rationalities" that shape and determine communal values and choices around research inquiry. In this view, power both includes and excludes discussions of choices around ethical and aesthetic ends, including the highest good, making these excluded ends illegitimate or mere add-ons to the seemingly more important questions around logical choices. Power thus governs the development and reconfiguration of research practices including the very strategies by which different individuals interact with each other, as well as where

\footnotetext{
${ }^{3}$ Aristotle acknowledged the importance of critical common-sensism in phronesis (Aristotle 2006: Book B, Paragraph 6).

${ }^{4}$ A similar argument is made by Habermas through his discourse ethics (for an extensive review and application in IS research, see Mingers and Walsham 2010). The key difference between Habermas' critical theoretical approach to understanding power and the pragmatic approach we propose here is that, in the former more emphasis is placed on discourse (ex ante), whereas in the latter more emphasis is placed on evolutionary experience (ex post) (see Apel 1995).
} 


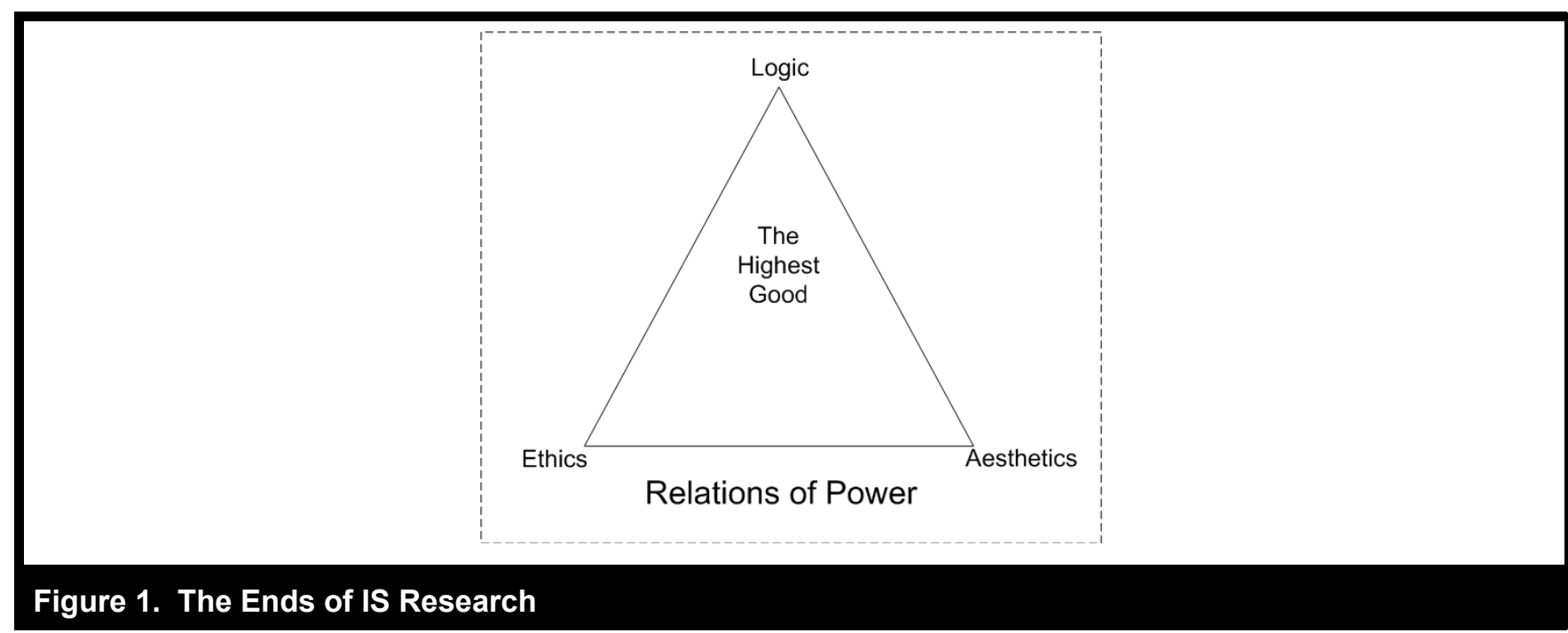

and with whom one chooses to do their research, around which topics, and published in which outlets.

\section{Linking the Ends of Research Inquiry to IS Research Practice}

The above discussion can help us examine IS research practices and research commentary from a revised view. For example, the discussion about the identification of possible ends for IS research through core concepts, topics, and research approaches which should preoccupy IS researchers (Benbasat and Zmud 2003; Ives et al. 2004; Weber 2006) can be seen as attempts to reformulate the logic, ethics, aesthetics, and highest good of the field. In these attempts, the aim has been to deal with the need to stand out and to be influential, and to be recognized as a serious discipline with core knowledge that others, including colleagues and practitioners, will find valuable. While standing out and having something of value is an indicator of success, it is perhaps secondary to specific ends we hope to achieve. Questions can also be raised about whether popularity with primarily other social scientists is important in having an enduring and long-term impact on the practitioner and policy communities we wish to serve.

In reply to arguments toward defining the core of IS research, others have argued that the social structure of the IS field is composed of multiple interacting communities of practice and knowing (CoP\&K) (DeSanctis 2003; Klein and Hirschheim 2008), and this diversity is important to the richness of the discipline (Robey 1996). While diversity is important, the multiple CoP\&K in the IS field must also work collectively toward the realization of the highest good. This is the transcendental outcome of our collective practices and their ability to transform the diverse communities that are and could be served by IS researchers. Thus, our efforts should not be to embrace diversity for diversity's sake. Rather IS researchers should strive to achieve "the legitimacy of accepted knowledge or state of the art practices" (Klein and Hirschheim 2008, p. 284) by illustrating the value of diversity in addressing the broader interests of the many CoP\&Ks within the IS field, and not only an increasingly smaller subset of people. Relevance would then be measured by an ability to convince many other CoP\&Ks that the work reveals desirable and collective ends important to the IS field.

In response, we propose a pragmatic framework (as illustrated in Figure 1) which sensitizes researchers to individually and collectively question the various ends of IS research.

Following on from our discussion of Peirce's process of research inquiry, our framework focuses on the choices and value judgements IS researchers make around logical ends (i.e., approaches to reasoning), ethical ends (i.e., methods of conduct), aesthetic ends (i.e., the anticipated and desirable outcomes), and the highest good (i.e., the long-term impact of the collective body of research beyond a single site and the concerns of a local community). The highest good occupies the middle of our figure because it is the emergent and collective realization of what is produced and meaningful to a community of inquiry through its diverse and collective practices (CP 5.433). At the same time, because these ends are shaped by and within power relations, as manifested in various rationalities of action, including publication policies, funding schemes, etc. (Flyvbjerg 2001), we consider such 
power relations to surround the four ends. By placing the four ends in a triangle, we also want to emphasize the strong interdependencies between them, and the complementary and competing relationships among them.

In the framework, we place great emphasis on written documents (e.g., journal articles) as these texts represent the ground, the intentional structure behind Peirce's process of inquiry that mediates communal practices (Robichaud 2006). Although not the only form of public expression for IS work, these texts are key in understanding the ways by which IS researchers represent and justify particular types of choices and value judgments about the ends of IS research while ignoring others. While some may suggest that there is little opportunity in restricted journal article space for researchers to explicitly discuss many of their choices and value judgments, we would argue that the scarcity of space is a good place to explore what is valued, and to be reflective about the conduct and representational practices of our research (see Golden-Biddle and Locke's [1993] proposed dimensions for writing convincing ethnographic texts).

We believe our pragmatic framework opens up the layers of interdependent ends for IS research, which need to be engaged individually and collectively across our research choices. At a minimum, the framework calls for more reflective research practices by raising our awareness of the various ends of IS research. More importantly, however, our pragmatic framework heightens our sensitivity in probing into the history and consequences of our choices leading to a more informed understanding and potential transformation of the situated ends of IS research.

In the next section, we draw on this pragmatic framework in an analysis of the ends of experimental IS research for illustrative purposes. Our purpose is not to reveal some fundamental flaw in experimental research (or any IS research methodology for that matter), but to indicate how all research involves choices and value judgments about our topics, about our design and execution of research studies, and about how we represent our results. In doing so, we illustrate how any research project anticipates and realizes ends within and beyond what the authors say, and how this pragmatic questioning can be used to question and shape the ends and consequences of IS research.

\section{A Pragmatic Redefinition of the Ends of Experimental Research}

Our questioning of experimental research is meant to open up a space of dialogue about the value choices we make around the ends of IS research, and to explore alternative and transformative possibilities. We, thus, provide two viewpoints throughout our discussion. The first viewpoint sympathetically explores the choices about the ends of IS research in these experimental papers. The second viewpoint reflects more critically on those choices (logic, ethics, aesthetics, and the highest good) and the power relations which may be surfaced and challenged by this alternative view.

In this effort, we focus on three choices made by IS researchers before, during, and after they complete their research: choices around IS topics, choices around designing and executing a research project, and choices about ways of representing the research in publication outlets. We explore these choices in relation to the four ends of IS research, including the ways by which these ends become conditioned by power relations. Table 1 provides a summary of our analysis.

\section{Choosing an IS Topic That Can Be Studied Experimentally}

Logic. In choosing and framing an IS topic, experimental researchers are committing to certain logical assumptions that condition the types of IS phenomena that can be studied experimentally. Particularly important here are the theories required to deduce hypotheses, and the methodologies used to test the hypotheses, mostly in an attempt to produce generalizable knowledge about the topic. The goal of experimental research is to establish cause-and-effect laws by isolating significant causes of important outcomes.

A sympathetic view would argue that experimental thinking provides clear guidance as to how to study particular IS phenomena, and a way of identifying and using theories to produce the hypotheses worth testing. It is also implicitly assumed that much of human progress has been based on the experimental methodology, especially through its success in the physical sciences.

A more critical view would examine how the topics chosen are, in a sense, already circumscribed by the requirements of experimental procedures, placing restrictions on which IS phenomena can and should be studied, including the depth of study. For example, although the study of IT-mediated learning has long been the focus of experimental research (e.g., Alavi 1994; Kanawattanachai and Yoo 2007), there have not been many (if any) experimental studies exploring learning as a social construction within community processes (Brown and Duguid 1991; Lave and Wenger 1991). One possible reason for the lack of such studies is that social construc- 
Table 1. A Pragmatic Redefinition of the Ends of Experimental Research

\begin{tabular}{|c|c|c|c|c|}
\hline $\begin{array}{c}\text { Key Sets of } \\
\text { Research Choices }\end{array}$ & $\begin{array}{c}\text { Logic: the theories } \\
\text { and methodologies } \\
\text { we use to structure } \\
\text { knowledge }\end{array}$ & $\begin{array}{l}\text { Ethics: the ethical } \\
\text { methods of conduct we } \\
\text { employ to carry out } \\
\text { research }\end{array}$ & $\begin{array}{c}\text { Aesthetics: the } \\
\text { desirable outcomes of } \\
\text { our research }\end{array}$ & $\begin{array}{l}\text { Highest Good: the long- } \\
\text { term impact of the } \\
\text { research beyond a single } \\
\text { site and topic area }\end{array}$ \\
\hline $\begin{array}{l}\text { Choosing an IS } \\
\text { topic to be studied } \\
\text { experimentally } \\
\text { Experimental } \\
\text { research (ER) } \\
\text { assumes that } \\
\text { generalizable } \\
\text { knowledge about a } \\
\text { topic is possible and } \\
\text { desirable through } \\
\text { experimental designs }\end{array}$ & $\begin{array}{l}\text { Sympathetic view: } \\
\text { ER provides a clear } \\
\text { set of theories and } \\
\text { existing knowledge } \\
\text { to guide the study of } \\
\text { IS phenomena. } \\
\text { - Critical view: How } \\
\text { do these logical } \\
\text { assumptions affect } \\
\text { the topics we can } \\
\text { study, and how do } \\
\text { they restrict our view } \\
\text { of these topics? }\end{array}$ & $\begin{array}{l}\text { Sympathetic view: ER } \\
\text { procedures provide explicit } \\
\text { ways and norms for formu- } \\
\text { lating and choosing topics } \\
\text { around existing theory and } \\
\text { deductive methods. } \\
\text { Critical view: Does the } \\
\text { deductive approach force } \\
\text { topics too quickly into pre- } \\
\text { existing theoretical views, } \\
\text { and how does it exclude } \\
\text { participant influence over } \\
\text { topics? }\end{array}$ & $\begin{array}{l}\text { Sympathetic view: the } \\
\text { objective and stable } \\
\text { knowledge of a topic will } \\
\text { hold across new } \\
\text { settings, and will } \\
\text { support further study. } \\
\text { - Critical view: are our } \\
\text { knowledge and topics } \\
\text { so easily amenable and } \\
\text { productively trans- } \\
\text { formed by a general } \\
\text { form of knowledge? }\end{array}$ & $\begin{array}{l}\text { Sympathetic view: ER } \\
\text { provides a way of building } \\
\text { a cumulative, long-term } \\
\text { understanding about a } \\
\text { topic. } \\
\text { - Critical view: does ER } \\
\text { contribute to a cumulative } \\
\text { tradition around a topic, } \\
\text { and if so, does it over- } \\
\text { emphasize our conser- } \\
\text { vative tendency towards } \\
\text { historical topics? }\end{array}$ \\
\hline >Power Relations & \multicolumn{4}{|c|}{$\begin{array}{l}\text {-What are the power relations that are shaping our topics (e.g., funding, publication, disciplinary control)? } \\
\text { - Would these choices still be made under any or all possible circumstances? }\end{array}$} \\
\hline $\begin{array}{l}\text { Designing \& } \\
\text { Executing the } \\
\text { experiment }\end{array}$ & $\begin{array}{l}\text { Sympathetic view: } \\
\text { ER enables the } \\
\text { deductive use of } \\
\text { theory to find precise } \\
\text { cause-and-effect } \\
\text { phenomena. } \\
\text { - Critical view: are } \\
\text { phenomena so } \\
\text { easily amenable to } \\
\text { primary causes? }\end{array}$ & $\begin{array}{l}\text { - Sympathetic view: ER } \\
\text { procedures provide clear } \\
\text { researcher \& subject con- } \\
\text { duct toward an objective/ } \\
\text { unbiased view of } \\
\text { phenomena. } \\
\text { - Critical view: How are } \\
\text { negative effects handled (if } \\
\text { at all), and how are the } \\
\text { experimental and control } \\
\text { subjects served and } \\
\text { involved (if at all) by and in } \\
\text { the experiment? }\end{array}$ & $\begin{array}{l}\text { - Sympathetic view: ER } \\
\text { outcomes are evaluated } \\
\text { by the rigorousness of } \\
\text { experimental } \\
\text { procedures and } \\
\text { statistical methods. } \\
\text { - Critical view: how } \\
\text { does experimental work } \\
\text { anticipate/ produce the } \\
\text { transformations desired } \\
\text { by the communities we } \\
\text { wish to serve? }\end{array}$ & $\begin{array}{l}\text { - Sympathetic view: ER } \\
\text { reveals cause-and-effect } \\
\text { "laws" through a collection } \\
\text { of studies expected to } \\
\text { have a long-term impact } \\
\text { on the people who read } \\
\text { and are informed by it. } \\
\text { - Critical view: is this } \\
\text { cumulative tradition pos- } \\
\text { sible or desirable given the } \\
\text { change in contexts, topics, } \\
\text { and CoP\&K? }\end{array}$ \\
\hline >Power Relations & \multicolumn{4}{|c|}{$\begin{array}{l}\text { - Were the subjects implicitly coerced into the experiment due to power asymmetries (e.g., use of students)? } \\
\text { - How are the subjects behavior shaped by the power asymmetries in the experiment? }\end{array}$} \\
\hline 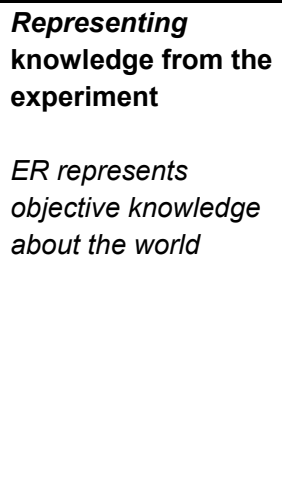 & $\begin{array}{l}\text { Sympathetic view: } \\
\text { Large methodology } \\
\text { sections illustrate } \\
\text { the rigor of theory } \\
\text { and findings, beyond } \\
\text { chance. } \\
\text { - Critical view: is this } \\
\text { an appropriate } \\
\text { representation of the } \\
\text { complex realities we } \\
\text { wish to portray and } \\
\text { inform? }\end{array}$ & $\begin{array}{l}\text { - Sympathetic view: ER } \\
\text { provides an ethical and } \\
\text { replicable account of the } \\
\text { research process by } \\
\text { clearly articulating } \\
\text { methods of conduct and } \\
\text { experimental limitations. } \\
\text { - Critical view: how does } \\
\text { this formalized way of } \\
\text { representing experimental } \\
\text { studies affect the ability to } \\
\text { report other ethical } \\
\text { issues? }\end{array}$ & $\begin{array}{l}\text { - Sympathetic view: } \\
\text { useful knowledge is a } \\
\text { text which renders } \\
\text { stable concepts that will } \\
\text { be present in numerous } \\
\text { settings into the future. } \\
\text { - Critical view: is the } \\
\text { stability of interpretation } \\
\text { either possible or } \\
\text { desirable? }\end{array}$ & $\begin{array}{l}\text { - Sympathetic view: ER } \\
\text { texts "add up" to a stable } \\
\text { and ever-increasing } \\
\text { understanding and control } \\
\text { of IS phenomena. } \\
\text { - Critical view: is any } \\
\text { grand "adding up" of } \\
\text { knowledge either possible } \\
\text { or desirable? }\end{array}$ \\
\hline$>$ Pou & \multicolumn{4}{|c|}{$\begin{array}{l}\text { - Was the representation of the research results shaped by asymmetrical relations of power (e.g., funding, } \\
\text { publication, supervisory relations, disciplinary control)? }\end{array}$} \\
\hline
\end{tabular}


tionist approaches to learning are difficult (but perhaps not impossible) to study experimentally. Experimental research, especially because of a requirement for large sample sizes for statistical analysis, also tends to restrict our view of any particular topic to that which can be measured across time and space, something which suggests ethical choices.

Ethics. In employing primarily deductive reasoning, topics explored through experimental studies use theory to derive hypotheses within and around particular topics. In fact the entire conduct in experimental design is the experimental procedure which dictates this elaborate and fairly rigid approach to hypothesis formulation and testing.

A sympathetic view of experimental research would argue that this deductive approach connects the work in a community of practice, and offers a clear method of ensuring that topics are studied more systematically than they may have been in the past. It could also be argued that the true value of a research community is to produce theoretical vantage points and to provide methodologies which can address longstanding and controversial disputes in particular topic areas.

A more critical view would question whether the transformation of topics into testable and established theories is always a good thing to do, and whether some contemporary topics may need to be studied in a less theoretically intensive way at the outset. It would also question whether a methodology, driven by researcher-led theoretical concerns and evaluated within primarily a researcher-led community, can produce the types of results that would help to realize aesthetic ends and the highest good.

Experimental research also tends to exclude voices other than those of the experimental researchers in the decision to study particular IS topics experimentally. Involving a broader CoP\&K in the decision to study particular IS topics would also require a broader discussion with other experimental researchers who may reject such research studies on grounds of insufficient experimental control (Fawcett 1991). In response, this type of inclusion may require using different (not lesser) rules of engagement and a switch from the "proof game" to the "plausibility game" with reviewers (Baer 1985, cited in Fawcett 1991). This brings us to a discussion about the aesthetic choices in the selection of IS topics to be studied experimentally.

Aesthetics. One of the desirable outcomes of experimental research is its internal validity, the degree to which the treatment, representing a cause, is solely responsible for the effect. Thus, even though most researchers acknowledge the limitations of experimental results and a need to replicate the work in natural settings (see Alavi 1994; Dennis 1996; Dennis and Garfield 2003; Hui et al. 2007), an experiment is meant to increase the validity of particular cause-and-effects.

A sympathetic view would argue that this focus on a causeeffect relationship produces clear results and findings that will be important in many other settings and is an important step in the accretion of understanding and the support of further research.

A critical view would question whether most of our important and emerging topics are so amenable to existing theory, and whether a general and stable form of knowledge is both possible and productive in transforming our view about the topic. Perhaps new phenomena, or even old phenomena for that matter, require a break from established and existing theory in order to produce the greatest transformation in our collective thinking at any given time. Other aesthetic goals, beyond the production of stable and generalizable knowledge, may be better suited or positioned for different topic areas to address important issues. For example, as mentioned earlier, although there have been many experimental research studies of the impacts of IT on student learning, there has been very little research (if any) on which forms of electronic learning are most important for students and how technology can specifically address their needs during those instances (i.e., beyond distinctions between electronic versus nonelectronic toward specific forms of electronic learning). An emphasis on alternative aesthetic ends would also help to identify the conditions upon which to realize the highest good of the research, which we discuss next.

The Highest Good. The highest good of the research is distinct from aesthetic ends in that it refers to implications beyond a single research paper and topic area and a short period of time, opening up a space for debating broader concerns across the IS field. In the case of experimentally based approaches across topic areas, the research is meant to add up to a cumulative understanding of the topics of importance to diverse CoP\&Ks.

A sympathetic view would argue that this summing up of experimental studies within a rigorous and well-defined methodology does add up to long-term results and implications for the various CoP\&Ks to be served.

A critical view may question whether topics remain stable across time, and if so, how our examination of topics through particular theoretical views produces the type of illumination and transformation we had hoped to achieve. A related critique would be whether and how work derived only from experiments could achieve transformation across diverse $\mathrm{CoP} \& \mathrm{Ks}$, without further studies using alternative methodo- 
logies. For example, Nunamaker et al. (1996) explore their experience with experimental research around the topic of group support systems (GSS) after "having worked with more than 200 public and private organizations in our own four meeting labs, as well as at over 1500 sites around the world that have been built upon the meeting lab model established at Arizona" (p. 169). The authors discuss lessons learned and lessons yet to be learned. Through this discussion it becomes evident that the benefits of GSS were, in most experiments (whether in the lab or the field), short-lived and contained in one or only a few sites. Despite expectations that further research would explore key issues in more depth, research interest on GSS has since dropped significantly (see Ramiller et al. 2008). While such an outcome may be hard to predict in advance, it forces one to inquire deeper into how topics are chosen, maintained and dropped, and to explore the long-term impacts from our work on the communities we wish to serve, within and beyond a single topic.

Power Relations. At this point it becomes important to consider the power relations that condition our choices across logical, ethical, and aesthetic ends, as well as the highest good. Taking GSS studies as an example, one could argue that it was the deliberate effort of a particular $\mathrm{CoP} \& \mathrm{~K}$ within IS to set an agenda for experimental research so that it appeared to be situated beyond ethics and questions of aesthetics toward an objective account of emerging IS phenomena (Ramiller et al. 2008). In the same review of GSS research, Ramiller et al. (2008) add that "GSS received much of its initial impetus from externally-funded academic research centers, where the earliest GSS technology was built and later transferred, in a limited fashion, to industry and government" (p. 13).

This dynamic between specialized academic interests (such as discipline, tenure requirements, journal rankings, academic freedom, etc.) and "industry bandwagons" (Ramiller et al. 2008) suggests that research topics are selected and investigated within particular political settings, through shifts in government, corporate, and public investment in research. Especially now, research funding bodies appear to be setting the agenda for researchers around specific topics and types of research projects, while also setting clear ethical frameworks for researchers to follow in achieving specific outcomes (e.g., ESRC 2005). Although this may appear to be a much-needed and positive development, the setting of topics in such an explicit and structured way suggests that IS researchers have left others to set the research agenda. By claiming neutrality to ethics and higher ends, there is a risk that researchers are increasingly becoming technicians, with a set of tools and theories ready to investigate the ends of other powerful and well-funded groups.
We next explore the implications of such neutrality in the context of choices around the design and execution of experiments.

\section{Designing and Executing the Experiment}

Logic. As discussed above, experimental research tends to follow a formalized and programmatic logic when choosing an IS topic, and when designing and executing an experiment. This logic includes a clear indication of extant theory and the hypotheses which derive from it, the identification of independent and dependent variables (and control variable if required), and the description of experimental treatment and controls which are derived from this theory.

In one well-cited and well-executed example of experimental research, Alavi (1994) investigated the impact of a group decision support system (GDSS) on student learning and their evaluation of classroom experiences. The text emphasizes the procedures used to illustrate how the treatment subjects were equipped with GDSS hardware and software, whereas control subjects used a "traditional" classroom setting. The text also emphasizes control through the use of post-experiment analysis which indicates that there was no significant difference in the students' backgrounds (Alavi 1994, p. 164). The results show that student learning was statistically (beyond chance) better in the GDSS compared with the non-GDSS group.

A sympathetic view would argue that following such a structured logic allows experimental researchers to focus on important and established cause-and-effect factors, found within other research CoP\&Ks.

A more critical view would question whether deductive theoretical work on its own can indeed find a set of primary causes within a particular topic area that will be important across many other contexts. The smaller but still significant problem is then controlling for these many other important and alternative causes in an experiment.

More importantly, one could question how experimental methodologies exclude experimental subjects (e.g., students) from decisions around the design and execution of experiments toward particular causes and effects. We explore such exclusion practices next within a consideration of the ethical choices involved in designing and executing experiments.

Ethics. Experimental researchers are expected to be neutral observers who can uncover objective knowledge that is true beyond a doubt. To do so, there is a need for the experimenter to emphasize empirical observation in order to objec- 
tively test theory (McGrath 1982). This combination of theory and observation is matched by sophisticated techniques to remove or randomize the many other possible and correlated causes with the dependent variable (so-called confounding factors) so the research is left with results assumed to be the true causes and their effects. Double-blind procedures are also employed for ensuring that both researchers and subjects are unaware of the treatment effects (McGrath 1982).

A sympathetic view would argue that such experimental procedures are welcomed because they provide a clear set of ethical rules of conduct for both researchers and subjects in producing an objective and unbiased view of IS phenomena. In one example of a field experiment, the researchers sought to assess whether consumers in Singapore valued privacy statements and privacy seals and whether such privacy practices affected consumer disclosure of personal information (Hui et al. 2007). Different types of privacy assurance were randomly shown to a group of subjects who were asked to browse an experimental website and provide some personal information. In an effort to ensure the outcomes were statistically generalizable beyond "anecdotal evidence," the whole experiment was disguised. "Subjects were told that their responses to the survey would help design future products and promotions" (Hui et al. 2007, p. 21). In fact, the experimental website did not provide a privacy statement about the experiment itself. Hui et al. (2007) explained these choices as being a contrast to similar studies carried out in Europe, because "privacy statements [in Singapore]...have no impact on consumer behavior," and they argued that this "could be due to differences in context" (p. 27).

A critical view would question whether IS researchers can resolve the tensions between an intervener and a neutral observer, and whether such a neutral stance is desirable in serving the communities we wish to serve. The researcher is often not simply on-the-scene to observe neutral facts, but is motivated by particular ends of interest to him or her, and a community of researchers. Thus, there is a need to explore the relationship between rewards, participation, and research objectives, especially if the topic is particularly prone to raise ethical issues such as privacy assurance (Hui et al. 2007).

Such a critical approach would mean a broader definition of the CoP\&K to be served by the research, beyond just the researchers. A critical approach would provide distinct advantages such as encouraging research on community development and systems change initiatives (e.g., initiatives on changing privacy policies on web sites), while transforming the processes of designing experiments, selecting and recruiting subjects, and establishing procedures for managing control and treatment variables. In such an approach, ethics can become an active and situated reflection (based on phronesis) rather than being outsourced to paper forms and committees.

The key ethical dilemma with such a critical approach to experimental research would be around the choices made between the validity of the research (e.g., how big should a representative sample be and how can we ensure subjects are unaware of the treatment?) and the values allowed to affect topic and intervention selection (e.g., which of the identified values in the representative sample should researchers pay attention to and how?). Once again, such an approach may require a switch from an effort toward unquestionable outcomes to plausible outcomes, while placing greater emphasis on engaging and dealing with ethical dilemmas emerging in the research (see Walsham and Sahay's [1999] discussion of the implications of their role as IS researchers including their research conduct for future intensive research studies in other organizational settings). This brings us to a consideration of the aesthetic choices made when designing and executing an experiment.

Aesthetics. As discussed earlier, one of the primary and desirable outcomes of experimental research is its internal validity, which is dictated by the rigorous execution of an experiment, and the use of statistical methods to illustrate cause-and-effect beyond chance.

As suggested already, a sympathetic view would argue that the rigorousness of experimental procedures produces knowledge that is beyond a doubt, important, and transformative to those who will read it. Cutting through the noise of what is often called anecdotal evidence of a particular case, experimental studies uncover cause-and-effect relationships which can be considered in numerous other settings.

A more critical view would question both the specific form of generalizability and the transformative possibility of a study. In the first instance, a focus on the internal validity of experimental research, as justified through rigorous methodological and theoretical execution, is what Lee and Baskerville (2003) identified as a misapplication of the concept of generalizability in IS research. Instead of taking advantage of other conceptions of generalizability more appropriate to the purposes of a given research inquiry, IS researchers are often driven to generate proven results that conform to the statistical, sampling-based conception of generalizability (Lee and Baskerville 2003, p. 224). Combined with the tightly controlled contexts that are required to isolate cause and effect, it is clear that experimental results, perhaps except when dealing with basic human psychology, are difficult to replicate outside of the lab. 
In terms of the transformation of practice, one could move away from the execution of studies around predetermined choices about theory derived primarily within a research community, and toward negotiated outcomes on the boundaries of seemingly diverse forms of life (see Boland and Tenkasi 1995). In the example of the study by Hui et al. (2007), although it is relevant to know different subjects' general behavioral responses toward privacy assurances (i.e., researcher theoretical needs), it would also be relevant to know different subjects' specific behavioral responses toward privacy assurances during specific e-commerce transactions (i.e., consumer practical needs). A broader consideration of the aesthetic outcomes of methodological procedures would also help to realize the highest good of the research beyond a single site and IS topic.

The Highest Good. Although experimental research is often confined within a laboratory setting, by repeating the same experiment in multiple lab settings while adjusting some of the variables, experimental researchers claim universal causeand-effect laws (see Nunamaker et al. 1996). Through this accretion mentioned already but beyond a specific topic, IS research would be able to develop a patchwork of knowledge about various IS phenomena that would add up to produce a more complete understanding of the field.

A sympathetic view would argue that experimental research is capable of adding up to a long-term transformation of practice by uncovering general laws that will hold across space and time.

A critical view would question whether a cumulative tradition is either possible or desirable, given that the topics and concerns of existing and potential stakeholders are shifting constantly. As historical reviews of GSS research have shown (Briggs et al. 1997; Nunamaker et al. 1996; Ramiller et al. 2008), the cause-and-effect laws uncovered by experimental researchers only consider a small set of real-world variables, and there is always a need to contextualize them in natural settings beyond the lab. Briggs et al. (1997) identify a number of issues that experimental research has traditionally taken for granted including ethical questions such as "when important decisions are made [electronically] by groups of unidentifiable individuals, who is accountable?" (p. 11), and aesthetic questions on desired outcomes such as "under what conditions do shared drawing [electronic] tools make a team more effective?" (p. 11). In addition, in relation to research on GSS-supported student learning, one phenomenon that seems to have escaped an in-depth examination is the process by which students learn, before such learning can be enhanced through GSS. Perhaps more explicit research into the processes of student learning could have spurred further work beyond the confines of a single technology while gaining support from IS researchers not necessarily interested in only GSS or experimental research.

Power Relations. The conduct of experimental study, whether intended or not, is imbued with power relations that shape both the researcher and the experimental subject. On the one hand, the behaviors and attitudes of the researchers are circumscribed in very significant ways by the experimental conditions beyond their control (in order to erase the subject, as it were). On the other hand, when analyzing the experimental data these "erased subjects" then need to reinsert themselves (their own subjectivity) in order to interpret and make sense of the data. Likewise, through the experimental set-up and execution, the research subjects may be configured to enact behaviors which they would not otherwise consider as meaningful, appropriate or even ethically acceptable (as the Milgram [1963] experiments demonstrated).

We next explore in further detail the omnipresence of power relations and how they condition our research practices by examining our choices in representing IS research practice and knowledge in publications.

\section{Representing Knowledge from the Experiment}

Logic. Experimental logic seeks to render predictable and understandable knowledge beyond anecdotal evidence. A process of rigorous peer review by other researchers, including experimentalists, ensures that the research community confirms the validity of the research in allowing or denying its appearance in IS publication outlets. The review puts great emphasis on the rigorousness (i.e., conformity to norms) with which the experiment was designed and executed, whether researchers report adequate control over the various variables they studied, and whether the theories chosen were adequately motivated by the latest research. As a result, methodological sections illustrating the stability, rigor, and replicability of the results tend to be large in volume - often larger than the results section, the discussion, or the practical implications.

A sympathetic view would argue that there is a need to spend substantial space and time to demonstrate how such knowledge is in fact knowledge beyond chance, and not an artifact of method or analysis. The proof is in the execution and disclosure of full experimental methods.

A critical view would question whether a long discussion of methodological choices is the best way to reach the communities we wish to serve. Without affecting the topic or con- 
duct of research, we could represent the findings in markedly different ways to appeal to, and transform, different CoP\&Ks .

We may also question whether the representation of experimental research does enough to grapple with the complex and messy reality of IS phenomena. For example, how close to organizational reality are the responses of master's students about work-based global virtual teams (e.g., Jarvenpaa and Leidner 1999)? That is, there are questions to be raised in relation to how we classify our knowledge, and how that knowledge can stand as a productive representation of the IS phenomena we purport to inform. In answering such questions we also need to consider the choices we make around the representation of ethical issues in experimental research.

Ethics. As mentioned earlier, in representing knowledge from an experiment, experimental researchers devote long sections to methodology where they explain how they were able to arrive at such knowledge. In later sections of published experimental research, researchers also discuss the limitations of their experiments and how they were able to deal with them or alternatively how future research can be more sensitive to them.

A sympathetic view would argue that experimental research, through a clear articulation of methods of conduct including the limitations faced by the experiment, is an ethical account and admission of what was done during the study, so the results should be replicable elsewhere.

A critical view would argue that this rather formulaic response to the ethical conduct of experiment design (such as informed consent, ethical committee clearance, etc.) may not allow the reporting of situated experimental practices that could affect the replication of findings. This response largely removes the ethical responsibility of researchers to report specific ethical issues that confronted the conduct of the study, which is also bolstered by the objective and uninvolved representation of the researcher. This contributes to an odd situation whereby ethics are in fact removed from writing, and representation becomes a strangely technical and creative exercise to fit the study specifics into a typical experimental representation.

Aesthetics. Experimental results are meant to render knowledge that will be read and interpreted similarly across readers. In doing so, the exposition is expected to prevent alternative readings through a clarity which reveals the desired objective knowledge. In turn, the emphasis in the text is on convincing the reader of the internal validity of the examined cause-andeffect relationship, which is purported to be worthy of publication.
A sympathetic view would argue that knowledge is by definition those concepts that are rendered stable and found to be useful in numerous settings in the future.

A critical view would question whether any text can render such a predictable adoption and interpretation of research findings, and whether such a goal is the most useful for the multiple communities we wish to serve. For example, how can an experiment of "a global virtual collaboration [between students] organized over a period of six weeks" produce a valid representation of knowledge about trust in virtual teams (Jarvenpaa and Leidner 1999, p. 794), especially when it has been noted that the outcomes of experimental research with groups that do not exhibit the characteristics of groups found in real organizations tend not to be generalizable (Nunamaker et al. 1996)? In contrast, we may wish to produce alternative and detailed implications of the research findings for different audiences, and actively encourage the appropriation of such knowledge in new circumstances in order to increase the transformative possibilities of our research. This leads to a discussion of the highest good.

The Highest Good. As we have noted earlier, experimental research across many topics is expected to add up to a complete and comprehensive view of the IS domain, and in doing so, it is meant to render the field more comprehensible.

A sympathetic view would argue that by representing work in this way, the results of our work can be added up and meticulously compared and contrasted to rule any future uncertainty about the development and implementation of information systems. The long-term impact of experimental research in terms of the stability and robustness of the results would provide a comprehensive how-to account for IS researchers.

A critical view would argue that the long-term impact of IS research is more likely to emerge through the generation of alternative and even conflicting visions of IS activity, and that the adding up of generalizable knowledge is both impossible and undesirable in its conservative form. This view implies that the usefulness of an IS text changes according to time and space, and that texts should be introduced to both understand and transform our vision and directions for IS activity through convincing representations of knowledge. Important here is to realize that our awareness of and various answers to the different ends of research inquiry will shift as we uncover new directions and possibilities for the highest good.

Power Relations. From this discussion it becomes evident that IS researchers are not free agents; rather, they are part of various institutional rationalities of action and they parti- 
cipate, at different times, in different CoP\&Ks, which support and propagate those rationalities in following specific representation practices. Acknowledging the omnipresence of power in our research is both constraining - in that no one can ever escape it, no matter how strongly we try to resist it - and liberating - in that power's omnipresence "relies upon a multiplicity of intricate institutional interdependencies [that]... enhance the possibilities for 'local' disruptions" (Knights and Vurdubakis 1994, p. 178). In other words, although we cannot escape the institutional rationalities of action that condition our research choices, we can at least disrupt them. These disruptions need to take place at the boundaries of different CoP\&Ks, whereby diverse interests and activities can be negotiated and agreed upon for common research outcomes in a process of perspective making and perspective taking (Boland and Tenkasi 1995). We next explore the possibility of IS researchers becoming active participants in such disruptions by questioning the relationships and forces that condition our research choices.

\section{Discussion and Implications}

The key objective of the analysis was to illustrate two viewpoints concerning the ends of experimental IS research, with one viewpoint being more appreciative of current answers to the ends of experimental research, and another viewpoint questioning these answers to provide alternative possibilities. Both the appreciation and critique arise from an examination of the topics chosen, the execution of the study, and the representation of the results, in relation to explicit or implicit responses to different ends as embedded within particular power relations.

In summary, experimental research aims at providing a structured approach to the execution of theoretical constructs and methods that are well-understood and transformative, and in providing structured representations of knowledge that require particular types of disclosure and admissions. In doing so, the driving of theory and hypothesis testing (logical ends), the distanced and remote conduct of the researcher (ethical ends), the rigorousness of the experimental procedures toward achieving internal validity (aesthetic ends), and the serving of academics and practitioners through the revealing of objective knowledge across experimental sites, but within the confines of specialized IS topics (highest good), allows researchers to reveal phenomena that are potentially important (i.e., replicability of results). The assumption that the research sits beyond questions of power through objectivity is also attractive and inspiring.

On the other hand, a more critical reflection on experimental research is concerned with the limits of any relatively taken- for-granted logical, ethical, and aesthetic ends, and a limited consideration of the highest good, as well as involved power relations. Specifically, various questions can be raised about the restriction of topics and their transformation through the needs for statistical power, the summing up of numerous studies to reveal a complete and unchanging insight about the world through design and execution, and the assumption that textual representation can and should represent stable knowledge. By both appreciating and critiquing the ends of IS research, we can open up a dialogue concerning the alternative ends for IS research that could productively transform the collective highest good across methodologies, paradigms, and IS topics.

We understand that many researchers may believe that their work is completed once the results are produced and published in journal articles. What happens beyond this methodological and theoretical project is felt to be neither their particular responsibility nor under their control. In turn, they may consider choices about ethics, aesthetics, and the highest good-including the relations of power in shaping these choices - to be more important to industrial participants than academics.

However, in taking pragmatism seriously, researchers must at a minimum regard research as involving choices and value judgments about how to conduct their work and toward which outcomes. In becoming aware that research involves not only choices about instrumental rationality (i.e., how to conduct a study), but also about value rationality (i.e., what do we study and who is affected by our work), attention to the higher ends and how they affect and are affected by our choices about theory and method needs specific attention. It is these other higher ends - ethics, aesthetics, and the highest good — which define what a community of inquiry is about and achieves, and thus they require more explicit attention.

Given this, we have already illustrated a range of actions that researchers can take to engage the consequences of their research. A sympathetic engagement would acknowledge that all research actions involve instrumental and value choices, without necessarily questioning these choices and the conditions which shape them. A more critical engagement would mean explicitly questioning who is served and under-served through the choices we make, and how these choices are shaped by various rationalities which restrict or enable the realization of particular ends in IS research.

\section{Choices Around IS Topics}

The first pragmatic step in considering research on a specific IS topic area is realizing that it is a choice. While recognition 
of it as a choice may not affect anything specific about what IS researchers do and write about in their papers, it does raise the immediate question of why this topic now? It also raises questions about what topics were considered before settling on this topic, and what were the opportunity costs of pursuing this topic over others.

As evident from our analysis of experimental IS research, choices around IS topics are usually initiated within particular research and practitioner community interests. However, as in the example of research on GDSS, there is rarely a substantial questioning of why this topic now and how it could contribute to a transformation beyond specific academic and practitioner implications (i.e., a better appreciation of the highest good, for example, questioning how research in GDSS-enhanced student learning contributes to learning more broadly). Without this type of exploration and questioning, both before and after the project is completed, the impact of IS research remains contained within a narrowly defined CoP\&K interested primarily in the execution of the research and, more specifically, the theory and methodology (i.e., logic) employed, without much attention to the other ends.

Moving away from this approach to choosing IS topics would require a more reflective engagement of the various interests involved in studying a specific topic, while excluding others. As soon as IS researchers begin to actively debate their choices of specific IS topics with other interested stakeholders, they will find themselves seeking to question existing power relations in terms of who sets the research agenda, for whom, and toward which ends. For example, IS researchers have acknowledged the concern over the pro-innovation bias in diffusion studies, which has questioned the political agenda of diffusing innovations to "laggards" and the need to challenge these assumptions during the conduct of research (Swanson and Ramiller 2004).

This extended reflection can move beyond specific topic areas to include broader reviews and critiques of the IS field. For example, extended reflection can be achieved through historical studies of the development and evolution of specific topics within various IS communities. It can also be achieved by conducting ethnographic research at the boundary where IS academics and industry representatives come together.

Finally, comparative studies of the parallel development of IS academic and industry discourses around various IS phenomena, and an exploration of how IS research texts draw on and depend on wider discourses within the field and in industry, could reveal various rationalities affecting past IS topics, while unearthing those influences still present today (Ramiller et al. 2008). Such reflective inquiries provide a way of teasing out and transforming crucial assumptions and influences, which tend to restrict the realization and pursuit of alternative topics and ends.

Within the university context, we as a discipline also have to ask ourselves how our disciplinary institutions, tenure processes, journal rankings lists, and so forth are acting to circumscribe a particular understanding of what is seen as good IS research - phenomena worthy of research that will get published in good journals.

\section{Choices Around the Design and Execution of IS Research}

The second most common set of choices we make is about the ways of thinking about, collecting, and analyzing the data from our research.

A first step in considering different research design and execution strategies in IS research is realizing that, once again, these are choices with consequences across different research ends. Much of an IS paper is spent on describing and convincing the reader that the design and execution is most appropriate for this particular topic at this particular point in time, and that the evidence represents a serious and a well-executed study. However, as discussed in the analysis of experimental research, once a research project is underway, IS researchers tend to overemphasize their methodological actions in a preparatory attempt to address what their colleagues and reviewers will want-typically evidence collected in a standardized and recognizable way.

A more critical engagement with methodology would be to think more carefully about how acting in these particular ways will produce evidence and effects that will lead to the types of transformation we and other participants desire. This would require a conscious and situated form of critique about the intended and revealed ends of the research while considering how the design and execution of the study will be perceived by other CoP\&Ks with alternative and even conflicting views. An important consideration here is that many of these CoP\&Ks are less interested in the specific execution of the study than in the importance and transformative possibilities from the study outcomes, and this immediately affects how we should wish to act in the future. For example, the use of action research in recent years is both a way of acting and intervening and a way of convincing non-researchers of the value of the research. Certainly the methodology is, on the surface, more recognizable to practitioners than many of the other methodologies we employ. 
In terms of the highest good, however, this doesn't mean that every methodology should follow an action research form. However, it does suggest that IS researchers should seek to experiment with and anticipate the possible ends and consequences of work conducted in different ways in an evaluation of possible findings and solutions "which would hold in the long run" (CP 5.209-211). Exploring the anticipated consequences of the research in advance would move the horizon beyond "will this get published in a top IS journal" to other consequences in terms of its influence on other topic areas, methodologies, and theories in the IS field. The collective research by Braa et al. (2004) is an indication of how a group of projects is brought together to consider a different highest good - a set of projects

to design, implement, and sustain HIS [health information systems] following a participatory approach to support local management of health care delivery and information flows in selected health facilities, districts, and provinces, and its further spread within and across developing countries (p. 343).

In engaging these research choices more reflectively, IS researchers will no longer be simply concerned with the situated relationship between the researcher and research subject, but also with the way that the researchers' activities take place within a broader field of knowledge production. In other words, even though at any particular point in time knowledge might be understood by a research community to be scientifically true (as in experimental research), knowledge is also recognized and questioned as a product of contested socio-technical practices, where different actors engage in a struggle to frame facts in particular ways (Knorr-Cetina 1999).

The key effort here would be to seriously acknowledge the inseparability of knowledge claims about particular theories and methodological practices within the IS field from the various CoP\&Ks producing these claims. In other words, the production of knowledge and the realization of the highest good is always associated with the exercise of power within and across CoP\&Ks within the IS field. Thus, the reflexivity of IS researchers around their research choices will have to start with a problematization of the conditions and consequences of the formation of those choices (Flyvbjerg 2001).

Thus, the key effort should be to not only uncover the facts emerging in situ from a research site, but more importantly to probe how those facts reflect upon the wider institutional and political context in which they are produced.

\section{Choices Around Representations of IS Research}

The third most common set of choices we make is around the ways of representing IS research in publication outlets. A first step here is to acknowledge that our choices about representation in IS research will generate certain consequences while avoiding others. While IS researchers may be unaffected or unwilling to change their representations and publication outlets, it is important to realize that the choices we make here individually and collectively indicate what we think is worth reporting and whom we wish to reach. By conforming to publication requirements, IS researchers unintentionally indicate what is of value and what is not, often ignoring how their textual choices have unintended consequences. This is especially true in cases where there are restrictions on journal space and the review team's preferences which prevent researchers from telling the whole story. ${ }^{5}$

The key challenge is how to make these choices more visible. IS researchers could improve their research by focusing on the ways in which the meaning of their research is and could be coproduced across author and audience. Naturally, IS researchers play an important authorial role in the meaning that is derived from their research. However, the research subjects also have a role to play, in addition to academic team members (e.g., closest colleagues, Ph.D. students and supervisors, reviewers, editors), and the consumers who read and make sense of the various findings of the research (e.g., funding councils, professional groups, other researchers).

To start with, more critical IS research should acknowledge that the meanings of texts are unstable and cannot be fully controlled by authors. "Reality appears to us in the form of a continuum...whose possibilities of determination no multitude of individuals can exhaust" (CP 6.170). Thus, the possibility of misinterpreting and reinterpreting a text is potentially unlimited; as texts "travel" through time and space they get reinterpreted and transformed (Eco 1994). In turn, a further question IS researchers need to ask is the role of research consumers in contributing to and transforming the meaning of the results of a research project. Dealing actively with this "consumerism" aspect of IS research texts across different audiences implies a more critical appreciation and involvement of the reader-consumer in the production of texts within the IS field, which is almost exclusively available only to IS researchers, oriented toward methodological persuasion and a singular interpretation.

\footnotetext{
${ }^{5} \mathrm{We}$ thank the associate editor for this point.
} 
In addition, realizing the difficulty of expanding current IS research texts, perhaps because we cling to printed journal formats, it may be necessary to support the production of various subtexts in other places around the core research article published in an IS journal. These could be virtual places where debate by the authors with other interested participants is possible. For example, dedicated wiki spaces could be established where researchers and others interested in specific topics could debate theoretical ideas, methodological practices, and empirical findings found in published IS research. These debates would help to open up the black box of review processes, by commenting on the comprehensibility and importance of the research, while identifying alternative interpretations, applied applications, and further reflection on areas for further research (Introna and Whittaker 2004; Ramiller et al. 2008). Authors could also use this space to engage the audience of their published research, thus actively dealing with the consumerism aspect of IS research, mentioned earlier. At a meta-level, these debates could also serve as spaces for reviewing knowledge across the IS field. Thus, within and beyond practitioner spaces such as MISQ Executive, we need to determine other ways of engaging other audiences - other researchers and practitioners - including the problems in collapsing such a broad group of community participants into a single category.

Important here is to realize that all IS research must be striving for a collective revealing of the highest good, otherwise we remain a fragmented group of separate and competing CoP\&Ks, divided by hard answers to theory and methods. That is, IS researchers need to consider the effects of their research beyond citations, and look at how and to what extent insights emerging from their research are absorbed (or not) into other research studies. Concerns about ritual and inappropriate citation suggest there may be problems with the absorptive capacity of other researchers in the IS field, let alone the concern about the various practitioners and their ability to be interested in, and to absorb, our collective insights. In embracing a more reflective engagement of IS research choices, IS researchers can use the pragmatic framework illustrated in Figure 1, as well as empirical questions similar to those found in Table 1, as a way of explaining and justifying the relevance of the research and in the process improving the absorptive capacity of other researchers.

In identifying the political and institutional limits of research knowledge, IS researchers would come to more explicitly acknowledge that discovering the truth is a matter of identifying, accepting, and resisting the academic and practitioner conventions, fashions, and conformist pressure that normalize the researcher and lead to the production of sanctioned research. The aim of IS researchers would be to recognize these conventions and, at the same time, seek to successfully navigate them through the artful deployment of rhetorical strategies (see Alvesson et al. 2008).

\section{Conclusion}

The aim of this research essay was to argue that any efforts to understand the state of the IS field has to necessarily consider the various choices and value judgments embedded in IS research. Drawing on the pragmatism of C. S. Peirce as well as recent conceptualizations of phronetic research, we pragmatically redefined the rigor-relevance debate in IS research by arguing for a systematic questioning not only about the largely dominant focus on the theoretical and methodological choices made by researchers, but also about the ethical methods of conduct around how and for whom we should act, the anticipated and desired outcomes of the research, the collective and long-term impact of the research for the communities we wish to serve and inform, and the ways in which our choices are fostered, shaped, and restricted by power relations.

As a means of illustration, we provided both a sympathetic and a more critical view of the ends of experimental research. Our analysis of the ends of experimental research, as well as our discussion of broader commentaries on the state of the IS field, pointed to the realization that even small, conservative choices around the ends of IS research can affect our research agendas with consequences on the ways in which knowledge is produced, represented, and (re-)interpreted by others in the IS field.

We then proceeded with the implications of our pragmatic framework by proposing some practical recommendations IS researchers can employ when questioning the choices they make around IS topics, designing and executing their research, and the means of representing knowledge in informing and transforming the communities they wish to serve, including academics and practitioners. In contrasting a sympathetic and more critical view of research topics, execution, and representation, we suggest that IS research cannot sit above and beyond ethics and considerations of value judgements - either by leaving it as taken for granted or by trying to locate it elsewhere (such as funding bodies and ethics committees). Instead, we suggest that IS researchers make choices all the time, with each and every action, and that these choices have important consequences. Given this, researchers must explore the immediate and long-term consequences of every choice they make across preferred logic- 
the traditional domain of focus - ethics, aesthetics, the highest good, and the ways in which questions and answers are conditioned by power relations.

In opening up the complex landscape of IS research ends, we must acknowledge that this will make the practice of research much more difficult. However, in making this submerged landscape visible, we are claiming that it is irresponsible to shun this complexity by allowing decisions to be made elsewhere (by methodologies, disciplines, supervisors, funding agencies, ethical committees, and so forth). It is the responsibility of each researcher to face this complex landscape that is in a very real sense undecidable (i.e., there is no single decision that can resolve it). Reflectively and phronetically working through this undecidability is our ethical burden, as Derrida (1999, p. 66) suggests:

there would be no decision, in the strong sense of the word, in ethics, in politics, no decision, and thus no responsibility, without the experience of some undecidability. If you don't experience some undecidability, then the decision would simply be the application of a programme [decided elsewhere]... ethics and politics, therefore, start with undecidability.

We believe we have provided the ground upon which such reflection and working through of this undecidability can take place. Given the emergent and situated nature of the ends of research inquiry, our purpose here is not to answer the question, what should we do now? Such attempts would suggest that we can somehow remove the burden of responsibility from others to engage in a reflective inquiry for their own specific research. That, we believe, would be irresponsible and unethical. We can, however, suggest that what is expected of responsible IS researchers is to actively engage all ends - to ask and reflect on the question, why should we do things in this way and what will be the consequences? Questioning the choices we make in our research, and setting our sights on the consequences emerging out of those, should increase our chances of individually and collectively revealing the relevant current and future ends of IS research.

\section{References}

Alavi, M. 1994. "Computer-Mediated Collaborative Learning: An Empirical Evaluation," MIS Quarterly (18:2), pp. 159-174.

Alvesson, M., Hardy, C., and Harley, B. 2008. "Reflecting on Reflexivity: Reflexive Textual Practices in Organization and Management Theory," Journal of Management Studies (45:3), pp. 480-501.
Apel, K-O. 1982. "C. S. Peirce and the Post-Tarskian Problem of an Adequate Explication of the Meaning of Truth: Towards a Transcendental-Pragmatic Theory of Truth, Part II," Transactions of the Charles S. Peirce Society (18), pp. 3-17.

Apel, K-O. 1995. C. S. Peirce: From Pragmatism to Pragmaticism, Amherst, MA: The University of Massachusetts Press.

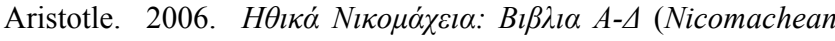
Ethics: Books 1-4), translated from Ancient to Modern Greek by Dimitris Lypourlis.

Baer, D. M. 1985. "Comment on Denkowski and Denkowski: Community-Based Residential Treatment of the Mentally Retarded Adolescent Offender," Journal of Community Psychology (13), pp. 306-307.

Baskerville, R. 1999. "Investigating Information Systems with Action Research," Communications of the Association for Information Systems (19:2), pp. 1-31

Baskerville, R., and Myers, M. D. 2004, "Special Issue on Action Research in Information Systems: Making IS Research Relevant to Practice-Foreword," MIS Quarterly (28:3), pp 329-335.

Benbasat, I., and Zmud, B. 1999. "Empirical Research in Information Systems: the Practice of Relevance," MIS Quarterly (23:1), pp. 3-16.

Benbasat, I., and Zmud, R. 2003. "The Identity Crisis Within the IS Discipline: Defining and Communicating the Discipline's Core Properties," MIS Quarterly (27:2), pp.183-194.

Boland, R. J., and Tenkasi, R. V. 1995. "Perspective Making and Perspective Taking in Communities of Knowing," Organization Science (6:4), pp. 350-373.

Braa, J., Monteiro, E., and Sahay, S. 2004. "Networks of Action: Sustainable Health Information Systems Across Developing Countries," MIS Quarterly (28:3), pp. 337-362.

Briggs, R., Nunamaker, J., and Sprague, R. 1997. "1001 Unanswered Research Questions in GSS," Journal of Management Information Systems (14:3), pp. 3-21.

Brown, J., and Duguid, P. 1991. "Organizational Learning and Communities of Practice: Toward a Unified View of Working, Learning, and Innovation," Organization Science (2:1), pp. 40-57.

Davenport, T., and Markus, M. 1999. "Rigor vs. Relevance Revisited: Response to Benbasat and Zmud," MIS Quarterly (23:1), pp. 19-23

Davison, R. M., Martinsons, M. G., Lo, H. W. H., and Kam, C. S. P. 2006. "Ethical Values of IT Professionals: Evidence from Hong Kong," IEEE Transactions on Engineering Management (53:1), pp. 48-58

Dennis. A. R. 1996. "Information Exchange in Group Decision Making: You Can Lead a Group to Information But You Can't Make It Think," MIS Quarterly (20:4), pp. 433-458.

Dennis, A. R., and Garfield, M. J. 2003. "The Adoption and Use of GSS in Project Teams: Toward More Participative Processes and Outcomes" MIS Quarterly (27:2), pp. 289-323.

DeSanctis, G. 2003. "The Social Life of Information Systems Research: A Response to Benbasat and Zmud's Call for Returning to the IT Artifact," Journal of the Association for Information Systems (4:7), pp. 360-376 
Derrida, J. 1999. "Hospitality, Justice and Responsibility: A Dialogue with Jacques Derrida," in Questioning Ethics: Contemporary Debates in Philosophy, R. Kearney and M. Dooley (eds.), London: Routledge, pp. 65-83.

Eco, U. 1979. The Role of the Reader: Explorations in the Semiotics of Texts, London: Hutchinson Press.

Eco, U. 1994. The Limits of Interpretation, Bloomington, IN: Indiana University Press.

Elkjær, B., and Simpson, B. 2006. "Towards a Pragmatic Theory of Creative Practice," paper presented at the Second Organization Studies Summer Workshop Return to Practice: Understanding Organization as It Happens, Mykonos, Greece, June 15-16 (available online at http://pure.au.dk/portal/files/58/ Elkjaer_Simpson_OS_2006.pdf).

ESRC. 2005. Research Ethics Framework, Economic and Social Research Council, Swindon, UK (http://www.esrc.ac.uk/).

Fawcett, S. B. 1991. "Some Values Guiding Community Research and Action," Journal of Applied Behavior Analysis (24), pp. 621-636

Flyvbjerg, B. 2001. Making Social Science Matter: Why Social Inquiry Fails and How It Can Succeed Again, translated by Steven Sampson, Cambridge: Cambridge University Press.

Flyvbjerg, B. 2004. "Phronetic Planning Research: Theoretical and Methodological Reflections," Planning Theory \& Practice (5:3), pp. 283-306

Flyvbjerg, B. 2006. "Making Organization Research Matter: Power, Values, and Phronesis," in The Sage Handbook of Organization Studies ( $2^{\text {nd }}$ ed.) S. R. Clegg, C. Hardy, T. B. Lawrence, and W. R. Nord (eds.), Thousand Oaks, CA: Sage Publications, pp. 370-387.

Golden-Biddle, K., and Locke, K. 1993. “Appealing Work: An Investigation of How Ethnographic Texts Convince," Organization Science (4:4), pp. 595-616.

Goles, T., and Hirschheim, R. 2000. "The Paradigm is Dead, the Paradigm is Dead...Long Live the Paradigm: The Legacy of Burrell and Morgan," Omega (28), pp. 249-268.

Gruender, D. 1983. "Pragmatism, Science and Metaphysics," in The Relevance of Charles Peirce, E. Freeman (ed), La Salle, IL: Monist Library of Philosophy, pp. 271-291.

Habermas, J. 1992. "Peirce and Communication," in Postmetaphysical Thinking, J. Habermas, translated by W. M. Hohengarten, Cambridge, UK: Polity Press, pp. 88-113.

Habermas, J. 1994. Justification and Application: Remarks on Discourse Ethics, Cambridge, MA: The MIT Press.

Habermas, J. 1998. On the Pragmatics of Communication, Cambridge, MA: The MIT Press.

Hausman, C. 1993. Charles S. Peirce's Evolutionary Philosophy, New York: Cambridge University Press.

Hirschheim, R., and Klein, H. 1994. "Realizing Emancipatory Principles in Information Systems Development: The Case for ETHICS," MIS Quarterly (18:1), pp.83-109.

Hirschheim, R., and Klein, H. 2003. "Crisis in the IS Field? A Critical Reflection on the State of the Discipline," Journal of the Association for Information Systems (4:5), pp. 237-293

Hui, K-L., Teo, H. H., and Lee, S-Y. T. 2007. "The Value of Privacy Assurance: An Exploratory Field Experiment," MIS Quarterly (31:1), pp. 19-33
Introna, L. D., and Whittaker, L. 2004. "Journals, Truth, and Politics: The Case of MIS Quarterly," in Information Systems Research: Relevant Theory and Informed Practice, B. Kaplan, D. P. Truex III, D. Wastell, A. T. Wood-Harper, and J. I. DeGross (eds.), Norwell, MA: Kluwer Academic Publishers, pp. 103-120.

Ives, B., Parks, M. S., Porra, J., and Silva L. 2004. "Phylogeny and Power in the IS Domain: A Response to Benbasat and Zmud's Call for Returning to the IT Artifact," Journal of the Association for Information Systems (5:3), pp. 108-124.

Jarvenpaa,S. L., and Leidner, D. E. 1999. "Communication and Trust in Global Virtual Teams," Organization Science (10:6), pp. 791-815.

Kanawattanachai, P., and Yoo, Y. 2007. "The Impact of Knowledge Coordination on Virtual Team Performance Over Time," MIS Quarterly (31:4), pp. 783-808.

King, J., and Lyytinen, K. (eds.). 2006. Information Systems: The State of the Field, Chichester, UK: John Wiley \& Sons.

Klein, H., and Hirschheim, R. 2008. "The Structure of the IS Discipline Reconsidered: Implications and Reflections from a Community of Practice Perspective," Information \& Organization (18:4), pp. 280-302.

Knights, D., and Vurdubakis, T. 1994. "Foucault, Power, Resistance and All That," in Resistance and Power in Organizations, J. Jermier and W. Nord (eds.), London: Routledge, pp. 167-198.

Knorr-Cetina, K. 1999. Epistemic Cultures: How the Sciences Make Knowledge, Cambridge, MA: Harvard University Press.

Kohlberg, L. 1981. Essays on Moral Development. Volume One: The Philosophy of Moral Development, San Francisco: Harper \& Row.

Krois, J. M. 1994. "C. S. Peirce and Philosophical Ethics," in Peirce and Value Theory: On Peircean Ethics and Aesthetics, H. Parrett (ed.), Amsterdam: John Benjamins Publishing Company, pp. 27-38.

Lave, J., and Wenger, E. 1991. Situated Learning: Legitimate Peripheral Particpation, Cambridge, MA: Harvard University Press.

Lee, A. 1999. "Rigor and Relevance in MIS Research: Beyond the Approach of Positivism Alone," MIS Quarterly (23:1), pp. 29-33.

Lee, A., and Baskerville, R. 2003. "Generalizing Generalizibility in Information Systems Research," Information Systems Research (14:3), pp. 221-243.

Liszka, J. 1978. "Community is C. S. Peirce: Science as a Means and as an End," Transactions of the C. S. Peirce Society (14:4), pp. 305-321.

Lyytinen, K. 1999. "Empirical Research in Information Systems: On the Relevance of Practice in Thinking of IS Research," MIS Quarterly (23:1), pp. 25-28.

McGrath, J. E. 1982. "Dilemmatics: The Study of Research Choices and Dilemmas," in Judgment Calls in Research, J. E. McGrath (ed.), Beverly Hills, CA: Sage Publications, pp. 69-80.

Mingers, J., and Walsham, G. 2010. "Toward Ethical Information Systems: The Contribution of Discourse Ethics," MIS Quarterly (34:4), pp. 833-854.

Milgram, S. 1963. "Behavioral Study of Obedience," Journal of Abnormal and Social Psychology (67:4), pp. 371-378. 
Mumford, E. 2006. "The Story of Socio-Technical Design: Reflections on its Successes, Failures and Potential," Information Systems Journal (16), pp. 317-342.

Nunamaker, J., Briggs, R., Mittleman, D., Vogel, D., and Balthazard, P. 1996. "Lessons from a Dozen Years of Group Support Systems Research: A Discussion of Lab and Field Findings," Journal of Management Information Systems (13:3), pp. 163-207.

Peirce, C. S. 1931-1958. Collected Papers of Charles Sanders Peirce (8 volumes): Volumes I-VI edited by C. Hartshorne and P. Weiss (Cambridge, MA: Harvard University Press, 1931-1935); Volumes VII and VIII edited by A. W. Burks (Cambridge, MA: Harvard University Press, 1958).

Ramiller, N. C., Swanson, E. B., and Wang, P. 2008. "Research Directions in Information Systems: Toward an Institutional Ecology," Journal of the Association of Information Systems (9:1), pp. 1-22.

Robichaud, D. 2006. "Steps Toward a Relational View of Agency," in Communication as Organizing, F. J. R. F., Taylor, and E. J. Van Every (eds.), Mahwah, NJ: Lawrence Erlbaum Associates, pp. 101-114.

Robey, D. 1996. "Diversity in Information Systems Research: Threat, Promise, and Responsibility," Information Systems Research (7:4), pp. 400-408.

Robey, D., and Markus, M. L. 1998. "Beyond Rigor and Relevance: Producing Consumable Research About Information Systems," Information Resources Management Journal (11:1), pp. 7-15.

Rosemann, M., and Vessey, I. 2008. "Toward Improving the Relevance of Information Systems Research to Practice: The Role of Applicability Checks," MIS Quarterly (32:1), pp 1-22.

Sfendoni-Mentzou, D. 1996. "The Reality of Thirdness: A Potential-Pragmatic Account of Laws of Nature," in Realism and Anti-Realism in the Philosophy of Science, R. Cohen and R. Hilpinen (eds.), Norwell, MA: Kluwer Academic Publishers, pp. 75-95.

Snell, R. S. 1996. "Complementing Kohlberg: Mapping the Ethical Reasoning Used by Managers for Their Own Dilemma Cases," Human Relations (49:1), pp. 23-49.

Stahl, B. 2008. "Discourses on Information Ethics: The Claim to Universality," Ethics and Information Technology (10), pp. 97-108.

Stuhr, J. J. 1994. "Rendering the World More Reasonable: The Practical Significance of Peirce's Normative Science," in Peirce and Value Theory: On Peircean Ethics and Aesthetics, H. Parrett (ed.), Amsterdam: John Benjamins Publishing Company, pp. 3-16.

Swanson, E. B., and Ramiller, N. C. 2004. "Innovating Mindfully with Information Technology," MIS Quarterly (28:4), pp. 553-583.

Walsham, G., and Sahay, S. 1999. "GIS for District-Level Administration in India: Problems and Opportunities," MIS Quarterly (23:1), pp. 39-66.

Weber, R. 2006. "Like Ships Passing in the Night: The Debate on the Core of the Information Systems Discipline," in Information Systems: The State of the Field, J. King and K. Lyytinen (eds.), Chichester, UK: John Wiley \& Sons, pp. 293-299.

\section{About the Authors}

Panos Constantinides is an assistant professor in Management Information Systems at Frederick University Cyprus. Before joining Frederick University, Panos held positions at Lancaster University's Management School and the Judge Business School at the University of Cambridge where he also earned his Ph.D. Panos has looked at IS development and implementation issues in different healthcare settings in association with different organizations, from British Telecommunications Health (UK), Synbiotix (UK and Cyprus), and the Institute of Computer Science at the Foundation for Research and Technology Hellas (Greece). His more recent research focuses on problems of collective action around the development of information infrastructures, and the coordination of multidisciplinary teams.

Mike Chiasson is currently an AIM (Advanced Institute of Management) Innovation Fellow and a professor at Lancaster University's Management School, in the Department of Management Science. Before joining Lancaster University, he was an associate professor at the University of Calgary, and a postdoctoral fellow at the Institute for Health Promotion Research at the University of British Columbia. His research examines how social context affects IS development and implementation, using a range of social theories (actor network theory, structuration theory, critical social theory, ethnomethodology, communicative action, power-knowledge, deconstruction, and institutional theory). In studying these questions, he has examined various development and implementation issues (privacy, user involvement, diffusion, outsourcing, cybercrime, and system development conflict) within medical, legal, engineering, entrepreneurial, and governmental settings. Most of his work has been qualitative in nature, with a strong emphasis on participant observation.

Lucas D. Introna is professor of Organization, Technology and Ethics at Lancaster University's Management School. His research interest is the social dimensions of information technology and its consequences for society. In particular he is concerned with the way information technology transforms and mediates social interaction with specific reference to the moral dimension. He is coeditor Ethics and Information Technology and has served as associate editor for MIS Quarterly and Information Systems Research. He is also a founding member of the International Society for Ethics and Information Technology (INSEIT) and an active member of International Federation for Information Processing's Working Group 8.2 (Information Systems and Organizations), the Society for Philosophy in Contemporary World (SPCW), and a number of other academic and professional societies. His work includes a widely cited book, Management, Information and Power, and various academic papers in journals and conference proceedings on topics such as phenomenology, technology studies, theories of information, privacy, surveillance, information technology and post-modern ethics, autopoiesis and social systems, and virtual organizations. 
Copyright of MIS Quarterly is the property of MIS Quarterly \& The Society for Information Management and its content may not be copied or emailed to multiple sites or posted to a listserv without the copyright holder's express written permission. However, users may print, download, or email articles for individual use. 